\title{
EL FACTOR DE LA PRECIPITACIÓN EN LA FORMACIÓN DE AVENIDAS EN LA CUENCA ALTA DEL TURIA*
}

\author{
Jonatan Morell Cuevas \\ Departamento de Geografía, Universitat de València. Avda. Blasco Ibáñez no 28. \\ 46010 Valencia. Correo electrónico: jonatan.morell@uv.es
}

\begin{abstract}
Resumen: Los estudios hidrológicos realizados desde una óptica geográfica son escasos en nuestro país. Se analiza un aspecto particular de la hidrología en la cuenca alta del Turia. Así, se ha individualizado los principales episodios de avenida en aforos de la cuenca de cabecera. Se profundiza en sus aspectos morfológicos y sus características principales. Posteriormente se analizan aspectos meteorológicos, es decir, el análisis sinóptico y pluviométrico. Finalmente, se interrelacionan ambos análisis para establecer cómo se produce la conversión lluvia-caudal, que factores influyen en ella y su volumetría. También se valora el riesgo o recurso hídrico que suponen.
\end{abstract}

Palabras clave: cuenca fluvial, Guadalaviar, Alfambra, precipitación intensa, avenidas, escorrentía directa, volumen de precipitación, recurso hídrico.

\begin{abstract}
Hydrological research are unusually from geography in Spain. A particular aspect of hydrology is analysed in the high Turia drainage basin (Teruel). The principles events of floods has been individualized in the different measurement points of the head drainage basin. Morphological aspects and principles characteristics are more analysed. Also, meteorological aspects like precipitation and synoptic situation. Finally, we connect both analysis in order to establish how is the transformation precipitation-runoff, elements affecting and volumetric analysis. Risk and hydrological resource are too valorised.
\end{abstract}

Key words: drainage basin, Guadalaviar river, Alfambra river, heavy rainfall, floods, direct runoff, volume, hydrological resource.

* Recibido: 11-4-2001. Aceptado: 8-7-2001 


\section{Introducción y marco geográfico}

El fenómeno de avenidas asociado a precipitaciones intensas es muy común en los ríos de la vertiente mediterránea de la Península Ibérica. Todos estos ríos registran, de manera excepcional, caudales extraordinarios asociados a lluvias muy importantes por su intensidad y volumen de precipitación. El presente artículo se centra en el tramo superior del río Turia, una zona a caballo entre las comunidades autónomas de Aragón y Valencia.

La cuenca alta del Turia se sitúa entre los $0^{\circ} 36^{\prime}$ y $1^{\circ} 47^{\prime}$ de longitud w y los $39^{\circ}$ $52^{\prime}$ y $40^{\circ} 45^{\prime}$ de latitud $\mathrm{N}$. Tiene una superficie que abarca $6.394 \mathrm{~km}^{2}$. La mayor parte de su cuenca pertenece a la provincia de Teruel. Dentro de ella quedan englobadas las cuencas del Guadalaviar y del Alfambra, así como una parte de la del Turia y de otros ríos tributarios de éste. El resto de la cuenca, en su parte más meridional, se reparte entre las provincias de Valencia y Cuenca.

El relieve delimita y separa claramente esta cuenca de sus vecinas (Ebro, Mijares y Júcar). Se estructura en tres unidades principales bien definidas (Gutiérrez y Peña, 1990): la zona occidental de la cuenca, formada por la Sierra de Albarracín. Pertenece a la rama meridional o castellana de la cordillera ibérica. Posee una disposición NWSW y se prolonga hacia el sur a través de la Sierra de Javalón. La zona norte de la cuenca está constituida por una serie de sierras más modestas. La forman las sierras de Lidón, Palomera y Gúdar. Junto a esta última se sitúa, dentro de la cuenca y con dirección N-S, la Sierra del Pobo. El sector oriental de la cuenca viene definido por las sierras de Camarena y Javalambre. Todos los sistemas montañosos (menos la $S^{a}$ del Pobo) forman la divisoria de aguas del área de estudio.

Entre las sierras occidentales y las orientales se halla la depresión interna de Teruel-Alfambra. Esta fosa representa el eje central de la cuenca. Su continuidad estructural se encuentra en los llanos de Caudé, donde la depresión continúa por el valle del Jiloca. La altura media de la cuenca es muy elevada. Así la depresión se sitúa entre los 800 y $1200 \mathrm{~m}$., mientras que en los relieves que las franquean, se superan fácilmente los $1500 \mathrm{~m}$. Las mayores alturas son los $2020 \mathrm{~m}$. en el pico Javalambre y 2019 en el de Peñarroya (Gúdar).

La red fluvial queda jerarquizada por los dos colectores principales de cabecera, los ríos Alfambra y Guadalaviar (Morell, 1999). El primero drena todas las sierras septentrionales y la depresión homónima con una disposición NNE-SSW, mientras que el segundo desagua la Serranía de Albarracín, con un recorrido W-E. Ambas cuencas superan los $1000 \mathrm{~km}^{2}$ de superficie. La confluencia entre ambos se produce poco antes de llegar a la ciudad de Teruel. El valle del Turia recorre toda la depresión de Teruel-Alfambra con la misma dirección que el Alfambra. Recibe las aguas de importantes afluentes como los ríos Ebrón, Camarena, Ríodeva y Arcos. Estos 




Figura 1. Cuenca alta del Turia. Aforos: 1-Arquillo San Blas, 2-Alfambra en Teruel y 3-La Zagra. Elaboración propia

son de pequeño recorrido ya que fluyen de manera perpendicular al cauce principal del Turia, aunque en un reducido espacio tienen que salvar la diferencia altitudinal existente entre los relieves periféricos y la depresión central, por lo que muestran grandes pendientes. El régimen fluvial de todos los ríos es pluvio-nival con aguas altas a finales del invierno y primavera, corto estiaje y lenta recuperación durante el otoño. 


\section{Análisis de avenidas}

En este apartado se tratan las características principales de las 42 principales avenidas registradas en 3 aforos de la cuenca alta del Turia. El estudio se ha hecho a partir de los datos de caudal medio diario de los siguientes aforos de la red foronómica de la Confederación Hidrográfica del Júcar (CHJ):

1. Arquillo San Blas: embalse que regula las aguas del río Guadalaviar. Se sitúa en el término municipal de Teruel, junto a la pedanía de San Blas. Comenzó su funcionamiento en 1967. Hasta ese momento los caudales se medían en el aforo 8096 , situado aguas abajo muy cerca del embalse. Tiene una capacidad máxima de $22 \mathrm{hm}^{3}$. Drena una superficie de $926 \mathrm{~km}^{2}$.

2. Temiel-Alfambra (8027): situado en el término municipal de la capital provincial. Afora las aguas del río Alfambra poco antes de su confluencia con el Guadalaviar. Su cuenca alcanza una superficie drenada de $1396 \mathrm{~km}^{2}$.

3. La Zagra (8018): aforo del río Turia situado en el término de Tuejar (Valencia), en las gargantas por las que se encaja el río antes de entrar en el embalse de Benagéber. Es el aforo que cierra nuestra área de estudio. Cuenta con una superficie total de $4052 \mathrm{~km}^{2}$ que representan el $63 \%$ del total de la cuenca del Turia.

\subsection{Criterios de selección y delimitación}

El presente artículo no pretende analizar todas las variaciones bruscas de caudal que han registrado los ríos turolenses sino las crecidas más significativas. Definir a partir de cuándo podemos considerar un aumento importante del caudal como avenida y delimitarlo es tarea difícil y no exenta de impedimentos. Existen pocos estudios sobre crecidas que indiquen a partir de qué umbral se puede hablar de avenida. Muchos hidrólogos sólo estudian los casos extremos de avenidas de un río (Navarro, 1991). Sin embargo se ha tomado como referencia el estudio de Davy (1978) que considera avenida de un río cuando el caudal medio diario supera en 10 veces la media total del aforo durante el periodo estudiado. Así, se ha creado un fichero con todos los días que superan en un 1000\% el caudal medio en cada aforo. En el caso de La Zagra se ha rebajado esta cifra hasta el $800 \%$ dado que la cantidad de casos de avenidas era demasiado reducida, entre otros factores, por la laminación de avenidas.

El primer paso del análisis ha consistido en la valoración crítica de los datos registrados por la $\mathrm{CHJ}$. Las lagunas de información, aunque escasas, se han salvado mediante métodos de interpolación. A falta de datos instantáneos se trabaja con datos caudales medios diarios. Este tipo de datos enmascara grandes cambios de caudal 
producidos en el mismo día como los máximos instantáneos o la aparición de sucesivos picos de crecida. Pese a esta situación se trata de series de datos muy largas, continuas y completas, por lo que nos sirven para una primera aproximación al estudio hidrológico de una cuenca.

Otro problema es el consistente en delimitar los episodios de avenida. En el caso de cursos de agua efímeros, estudios recientes consideran duración de la avenida el tiempo en que existe circulación hídrica (Segura, 1990). Pero en ríos perennes vuelven a faltar estudios que traten este aspecto. La delimitación se ha hecho a partir del análisis individualizado de los hidrogramas de las diferentes avenidas. Así, se ha observado en qué momento se produce un aumento de caudal fruto de la escorrentía directa y cuándo ésta parece que desaparece del caudal base del río. Para definir este periodo en que circula la escorrentía directa se han analizado las partes más importantes del hidrograma, como son el día de inicio de la avenida $\left(D_{i}\right)$, el día de máximo pico $\left(D_{x}\right)$, y el día final del episodio $\left(D_{\mathrm{f}}\right)$.

a) Día inicial $\left(D_{i}\right)$ : es aquel que registra un incremento igual o superior al $30 \%$ del caudal del día anterior $\left(D_{i}-1\right)$. Lo consideraremos como primer día de avenida. A partir de este momento confluyen en el aforo dos tipos de flujo: el flujo basal y el de escorrentía directa. Es cuando comienza la fase de ascenso del hidrograma.

b) Día final $\left(D_{\mathrm{f}}\right)$ : es aquel en el que el descenso del hidrograma es todavía superior al $10 \%$ respecto al día previo, pero el día posterior $\left(\mathrm{D}_{\mathrm{f}}+1\right)$ ya registra un descenso inferior al 10\%. Marca el final de la fase de descenso del hidrograma y la desaparición de la escorrentía directa, por lo que el caudal del río se reduce al flujo basal.

c) Día de máximo pico de la avenida $\left(D_{x}\right)$ : es directamente aquel que registra el caudal diario medio más elevado de entre los días comprendidos entre $D_{i}$ y $D_{f}$ (periodo de avenida). Debido a que es una media del caudal en 24 horas, suele enmascarar cifras de caudales instantáneos mucho más elevados. Se considera como punto final de la fase de ascenso del hidrograma y como punto inicial de la fase de descenso de este.

Todos estos criterios de delimitación de avenidas se han contrastado en una serie de trabajos sobre avenidas de ríos mediterráneos (Palanca, 1998; Morell, 1999). Esto permite la comparación de resultados al tener una unidad de criterios que hasta ahora no se ha producido en nuestro ámbito de estudio.

\subsection{Principales avenidas en el periodo $1950-90$}

Localizadas y delimitadas todas las avenidas que cumplen los criterios anteriormente definidos, se han obtenido e individualizado un total de 42 episodios de ave- 
nida en los 3 aforos. Algunos episodios se registran en un único aforo y otros se dan en varios o en todos, aunque con un tiempo de desfase, según la distancia de cada aforo respecto al núcleo principal de precipitación dentro de la cuenca. También la forma del hidrograma (ver figura 2) y el caudal varían según los aforos. Debido a la gran cantidad de observatorios pluviométricos analizados y la gran extensión de la cuenca, no podemos hacer un análisis de los tiempos de respuesta pues no es conveniente extrapolar los datos de un solo observatorio para una lluvia que puede caer en una zona de más de $4000 \mathrm{~km}^{2}$.

A pesar de que se analiza la totalidad de la cuenca de drenaje del Turia, se tratan las avenidas de cada aforo de manera individualizada. La razón principal es poder diferenciar los comportamientos de las avenidas de los dos colectores de cabecera del Turia, es decir, Alfambra y Guadalaviar. Las avenidas están formadas por la escorrentía que se forma en una cuenca (output). Estas dependen no sólo de la precipitación o la fusión nival (input), sino de las características propias de cada cuenca: litología, pendientes, usos del suelo, etc. que influyen en la forma final del hidrograma.

Los episodios seleccionados son un total de 12 en el aforo del Guadalaviar de Arquilio San Blas, 17 en Teruel-Alfambra, y 13 en curso medio del Turia en La Zagra (ver cuadro 1). Cada episodio de avenida se nombra por la fecha del día que registra el máximo caudal del total de días que forman la crecida (Dx), es decir, el pico del hidrograma.

Teruel-Alfambra: 6-08-59

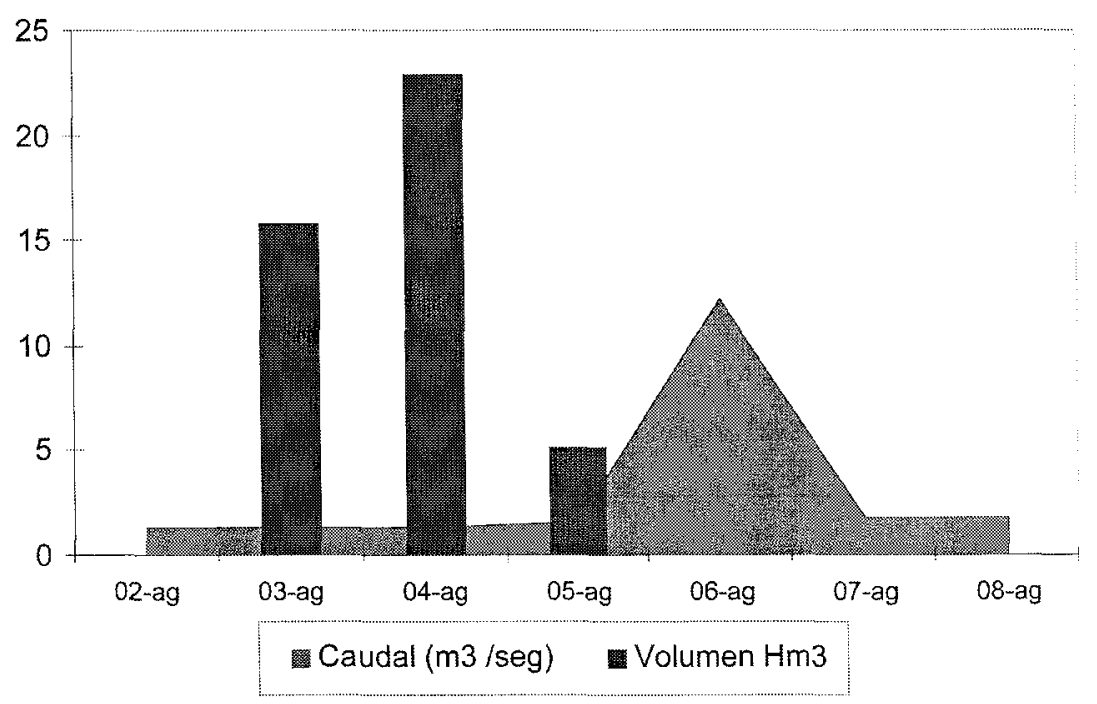

Figura 2. Ejemplo de hidrograma de una crecida del río Alfambra en el término de Teruel y el histograma del volumen de precipitación que la origina. Cabe notar que el tiempo de respuesta en esta cuenca es de más de dos días. Elaboración propia. Fuentes: INM y CHJ 


\subsection{Parámetros y características de las principales avenidas seleccionadas}

A partir del hidrograma se pueden analizar los parámetros de las avenidas. El hidrograma de una avenida es la representación gráfica de la evolución de los caudales en función del tiempo en una sección de un curso de agua (Manning, 1997). Se obtiene por el registro continuo de nivel y su posterior transformación mediante la curva de gasto (Ferrer, 1993). Posee una curva de diversa pendiente, explicada por las distintas aportaciones que lo conforman (Aparicio, 1999):

1. Escorrentía superficial: agua que proviene de la de los flujos laminar y concentrado, además de la caída sobre los propios cauces de la red de drenaje del río.

2. Caudal base: agua que procede del flujo subsuperficial (interflujo, según Ferrer, 1996) y del flujo subterráneo o profundo que realimenta el río en forma de surgencias y manantiales.

Las avenidas se clasificarán a partir de dos tipos de parámetros: por un lado los temporales (distribución anual y estacional), por otro lado los parámetros resultado de analizar el hidrograma atendiendo a su magnitud, duración, fase de ascenso y curva de agotamiento.

\section{A) Análisis temporal}

A partir de este análisis podemos destacar la concentración de las avenidas entorno a la década de 1951-60 en todos los aforos (Arquillo San Blas no posee datos de esta época). Las siguientes dos décadas tienen un número destacable de avenidas en el Guadalaviar, Alfambra y el aforo de confluencia de los dos ríos, pero apenas tienen relevancia en La Zagra. La concentración de varias avenidas coincide con años considerados húmedos y su ausencia con años secos. Casi no se registran avenidas durante el periodo 1981-90, por la presencia de una época de sequía muy marcada durante los primeros años de la década.

Una parte del análisis temporal es la clasificación según la estación del año en la que se produce el evento. Las avenidas registradas durante los meses de invierno son más destacables en el Guadalaviar ( $50 \%$ de los casos), seguidas de la primavera $\left(33^{`} 3 \%\right)$. El otoño y el verano tienen un número muy limitado de avenidas. En contraposición, en el aforo del río Alfambra las avenidas más importantes se producen durante las estaciones equinocciales en el $60 \%$, seguidas por el verano $(23 \% \%)$. Las de invierno son irrelevantes. En La Zagra las avenidas del invierno pierden importancia (por transmisión) y destacan las de primaveraverano. 
B) Magnitud (Q máx)

Es uno de los parámetros más sobresalientes que caracterizan a una avenida. Esta suele conocerse a partir del volumen de caudal registrado el día de pico de la avenida $\left(D_{x}\right)$. Los valores medios diarios enmascaran caudales instantáneos mucho más elevados que se producen durante períodos muy cortos de tiempo. Para comparar las diferentes cuencas analizadas hemos calculado un sencillo índice de caudal específico $\left(Q_{E D}\right)$ del día con más caudal de cada avenida atendiendo a la cuenca drenada por cada aforo. Así el valor de caudal máximo se ha multiplicado por $1000 \mathrm{y}$ se ha dividido por la superficie drenada por cada aforo. El resultado se expresa en $1 / \mathrm{seg} / \mathrm{km}^{2}$. A partir de este valor, consideramos avenidas ordinarias a las que tienen un QED inferior a 15, grandes entre esa cifra y 25 y extraordinarias a las que superan este último valor. Quedan fuera del estudio otras avenidas de pequeña magnitud.

De entre las avenidas del embalse de Arquillo San Blas, la mayor registrada durante el periodo de análisis es la de marzo de 1969 (ver cuadro 1). Esta registra el mayor $\mathrm{QED}_{\mathrm{x}}$ de las avenidas de los tres aforos $\left(60 \mathrm{l} / \mathrm{seg} / \mathrm{km}^{2}\right)$. Analizando el caudal específico diario vemos que no existe ninguna avenida de magnitud ordinaria. En cambio dominan las de magnitud grande, con $3 / 4$ del total de casos, y son representativas las avenidas extraordinarias.

Analizando los periodos de recurrencia que producen las avenidas en los tres aforos seleccionados, ver cuadro 2 , salta a la vista que las avenidas esperadas en el aforo del Guadalaviar pueden alcanzar magnitudes mucho más destacables que las del

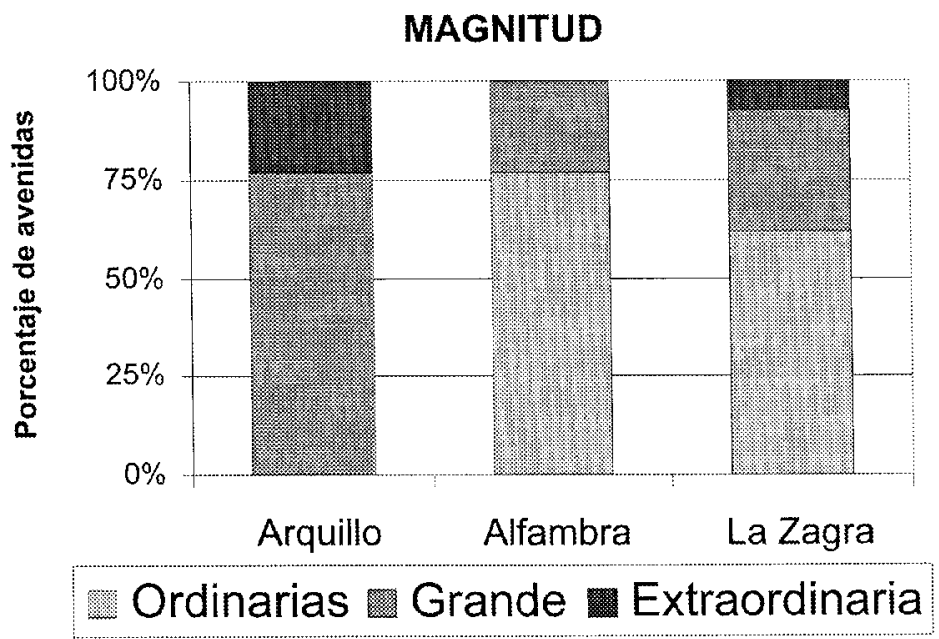

Figura 3. Porcentaje de avenidas según su magnitud. Fuente: CHJ. Elaboración propia 
Alfambra aun cuando se trate de periodos de recurrencia cortos. Así, la avenida esperada en el Guadalaviar con una recurrencia de 10 años casi duplica la magnitud de la esperada en el mismo periodo para el Alfambra. Las magnitudes de avenida esperadas en el Alfambra son bajas incluso para periodos de recurrencia de 50 años, mientras que en La Zagra y el Guadalaviar encontramos picos de crecida mucho más destacables.

Si comparamos estas avenidas con las que se producen en otros aforos de ríos vecinos con una cuenca receptora semejante, vemos que todas las avenidas de este río se pueden considerar como poco importantes. El río Cabriel a la altura del aforo de Pajaroncillo (08090) cuenta con una cuenca receptora de $829 \mathrm{~km}^{2}$. La mayor avenida del periodo 1950-90 se sitúa en marzo de 1969 y registra un QED de 202`5 $1 / \mathrm{seg} / \mathrm{km}^{2}$, una magnitud casi cuatro veces más elevada que la máxima alcanzada por el Guadalaviar.

El Alfambra registra 17 casos: 13 catalogados como ordinarias y 4 como grandes (ver cuadro 3). Cabe notar la ausencia de casos extraordinarios pues la máxima avenida apenas supera los $16 \mathrm{l} / \mathrm{seg} / \mathrm{km}^{2}$. Predominan las avenidas modestas por la forma y la situación de la cuenca: una depresión bien delimitada por relieves que producen pluviométrica bastante efectiva y la consiguiente falta de precipitaciones fuertes. La modestia de las avenidas que se producen en esta cuenca queda de manifiesto si las comparamos con las del río Mijares, vecino del Alfambra pero abierto a la influencia mediterránea. Éste, registra el 8 de agosto de 1968 un pico máximo de $225 \mathrm{~m}^{3} / \mathrm{seg}$ en el aforo del Terde con una cuenca receptora que representa la mitad de la del Alfambra.

La Zagra registra la avenida más importante durante marzo de 1969 con un pico de $107 \mathrm{~m}^{3} / \mathrm{seg}$. Es la de mayor caudal absoluto, pero en una cuenca muy grande por lo que su $\mathrm{QED}_{\mathrm{x}}$ es de $26 \mathrm{l} / \mathrm{seg} / \mathrm{km}^{2}$. Este es el único caso de avenida extraordinaria que registra este aforo. El resto se reparten en 4 avenidas grandes y 11 ordinarias.

Como acabamos de ver, el Alfambra, el Guadalaviar y el Turia, en su tramo más elevado, tienen avenidas destacables como todos los ríos de la vertiente mediterránea. Estas tienen mayores caudales en el Guadalaviar que en el Alfambra. Pero todas tienen una magnitud siempre modesta si las comparamos con aforos de características similares de ríos vecinos (Cabriel, Mijares y Palancia). Hay que destacar que el propio Turia puede producir avenidas muy destructivas, que alcanzan caudales importantes no en esta zona de estudio, sino en la cuenca baja. Esto es debido a que los episodios de avenida más virulentos se producen por lluvias de levante que afectan a las zonas litorales y prelitorales, pero que pierden importancia en la cuenca de cabecera.

\section{C) Duración total (Dt)}

Indica el número de días en que circula escorrentía directa. Avenidas normales son aquellas que tienen una duración similar a la mediana de cada aforo. En el embalse 
de Arquillo San Blas una avenida de duración "normal" dura 10 días. En el caso del Alfambra duran 9 días. Las avenidas normales en La Zagra tienen una duración inferior ( 7 días). Cuando mayor es la cuenca de recepción, menores son los días de duración de la avenida, pues aumenta la importancia del caudal base.

Las crecidas de larga duración son representativas en el río Alfambra ( $1 / 3$ de los casos dura más de 9 días), en el Guadalaviar éstas sólo representan el 16\% y son inexistentes en La Zagra. Las avenidas cortas son más frecuentes en La Zagra (58`3\%), seguidas por el Guadalaviar $(41,6 \%)$, mientras que en el Alfambra sólo representan el $23-5 \%$ de los episodios. La importancia de las avenidas de corta duración en La Zagra se debe al aumento relativo del caudal base en cuenca media y un descenso de los picos de crecida por traslación. Las avenidas que tienen el comportamiento de la media son el grupo más numeroso en todos los aforos. Cabe recalcar que las avenidas del Alfambra suelen ser más duraderas que las del Guadalaviar. Esto es debido a que el caudal base es mucho más elevado en este último tío.

a) La duración de la fase de ascenso o curva de concentración (Da) indica el tiempo de respuesta de la cuenca ante un episodio de precipitación. Depende de la forma de las características de la cuenca, como la distribución de la red de drenaje. También de la distancia del núcleo de las precipitaciones hasta el aforo y de las características de la precipitación. La duración normal de las fases de ascenso en todos los aforos se sitúa sobre 3 días. Si una avenida tiene una duración inferior a la media se considera de respuesta rápida, de respuesta normal entre 4 y 6 días y de respuesta lenta a aquellas que sobrepasan esta última cifra.

Analizando la distribución de las avenidas según estas categorías hay que destacar el dominio de las avenidas de respuesta rápida en las cuencas del

A)

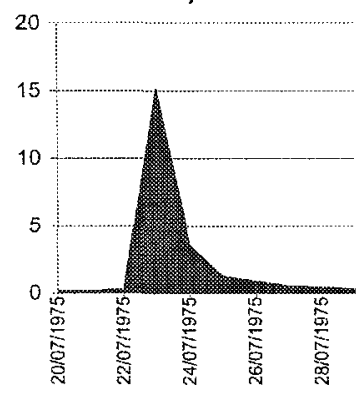

B)

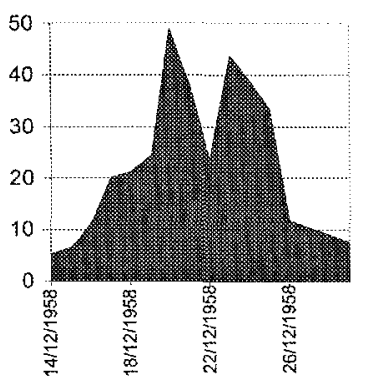

C)

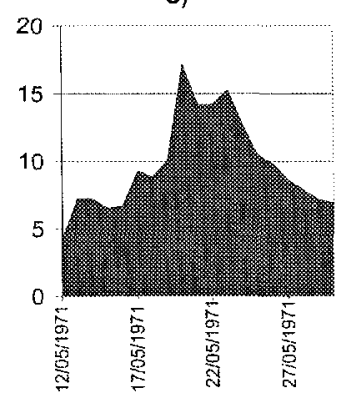

Figura 4. Tipos de hidrogramas en el Guadalaviar. El caudal se expresa en $\mathrm{m}^{3} / \mathrm{seg}$. A) hidrograma simple; B) hidrograma doble y C) hidrograma compuesto. Fuente: $\mathrm{CHJ}$. Elaboración propia. 
Alfambra (60\%), y Turia. En cambio, dominan más las de respuesta normal en el Guadalaviar (50\%, mientras que las de respuesta rápida sólo representan el $30 \%$ ). Las avenidas de respuesta lenta son poco numerosas en general.

b) En la fase de descenso (Dd) se produce una disminución más o menos rápida del flujo de escorrentía directa provocado por la avenida y un predominio cada vez mayor del flujo basal. La duración media de esta fase es de 3 días en las avenidas del Guadalaviar y la Zagra y 6 en las del Alfambra. Hemos dividido las avenidas según la duración de la curva de descenso en avenidas de caída suave, a las que duran entre 5 y 13 días, caída moderada, entre 3 y 7 días, y caída brusca, entre 1 y 4 días. La distribución de las avenidas según la duración de la fase de descenso en los diferentes aforos es bastante regular. Sólo queda remarcar que predominan los casos de avenidas de caída brusca en Arquillo San Blas, mientras que predominan los de caída normal en Teruel-Alfambra. En cambio los episodios de caída suave son escasos en todos los aforos.

\section{D) Forma del Hidrograma}

Los hidrogramas son la representación gráfica de los caudales durante un tiempo determinado en una sección de un curso de agua (Aparicio, 1999). En ellos confluyen varios tipos de escurrimiento: por un lado, el caudal base, proveniente de las aguas subterráneas y, por otro, la escorrentía directa, compuesta por flujos superficiales y de retorno. Según el número de picos que presenta cada hidrograma con sus respectivas fases de ascenso y descenso, los hemos clasificado en hidrogramas simples, dobles o complejos (ver figura 4). Los simples son los más habituales y numerosos en todas las cuencas. Representan más del $70 \%$ de casos en Alfambra y Turia. Son consecuencia de lluvias producidas en un tiempo bastante concentrado, típico de precipitaciones convectivas. Los hidrogramas dobles suponen pocos casos en Alfambra y Turia y no existen en el Guadalaviar. Por el contrario son muy abundantes los hidrogramas complejos en este último río, que representan más del $40 \%$ de las avenidas en este aforo. Los hidrogramas dobles responden a lluvias con intensidades repartidas en dos momentos. Los complejos responden al paso continuo de frentes atlánticos sobre la Sierra de Albarracín y por la forma concéntrica de la cuenca del Guadalaviar, que muestra poca preponderancia del cauce principal y relevancia muy elevada de afluentes como el rio Fuente del Berro o la Rambla de Monterde.

\section{Marco pluviométrico}

Se tratan las diferentes causas y tipos de tiempo así como la morfología de los episodios de precipitación, su reparto espacio-temporal y el volumen de agua precipi- 
tada sobre las diversas cuencas de drenaje durante cada episodio de avenida. Los datos de precipitación se han obtenido a partir de la red de observatorios del I.N.M..

\subsection{Precipitaciones medias}

Como ya se ha dicho, la zona de estudio se caracteriza por una contraposición entre el valle del Turia y las montañas periféricas que lo bordean. Esto tiene un fiel reflejo en el reparto anual de las precipitaciones. En la depresión de Teruel-Alfambra ningún observatorio supera los $500 \mathrm{~mm}$. (Teruel, $415 \mathrm{~mm}$; Torrebaja, $431 \mathrm{~mm}$ ). En cambio, en la cuenca del Guadalaviar las precipitaciones son muy elevadas: en una estrecha franja llegan a superar los $1000 \mathrm{~mm}$ anuales (Guadalaviar, $1064 \mathrm{~mm}$ ). En esta zona de cabecera se aprecia una fuerte disminución de la precipitación de W a E. Siguiendo el curso del Guadalaviar pasamos en menos de $15 \mathrm{Km}$ de los 1000 a los $400 \mathrm{~mm}$ anuales: en la cuenca media del Guadalaviar todavía se registran $732 \mathrm{~mm}$ en Terriente; en la cuenca baja apenas se superan los $500 \mathrm{~mm}$ anuales (Albarracín, $544 \mathrm{~mm}$ ) y pronto se baja por debajo de esta cifra (San Blas, $475 \mathrm{~mm}$ ). Esta diferencia se produce porque los Montes Universales forman una barrera orográfica que afecta a todos los frentes y advecciones procedentes del Atlántico. La precipitación disminuye a sotavento por efecto de sombra de lluvias. Las sierras orientales no son tan húmedas, al no estar tan bien expuestas a la circulación zonal. En Javalambre se superan los $800 \mathrm{~mm}$ en las zonas más elevadas y tan sólo se superan los $600 \mathrm{~mm}$ en Gúdar.

$\mathrm{Al}$ analizar el reparto estacional de las precipitaciones se puede dividir la cuenca en tres zonas pluviométricas:

1. Depresión intra-Ibérica de Teruel-Alfambra: zona situada entre 800 y 1100 metros. Se caracteriza por precipitaciones escasas (inferiores a $500 \mathrm{~mm}$ ) con un máximo principal en primavera, un corto estiaje y un mínimo muy marcado durante el invierno. El balance hídrico anual es deficitario gran parte del año por lo que se considera una zona casi semiárida.

2. Sierras Occidentales: incluye la Sierra de Albarracín, Montes Universales y $\mathrm{S}^{\mathrm{a}}$ de Javalón. Las precipitaciones son bastante abundantes y aumentan de 600 a $1000 \mathrm{~mm}$ anuales de $\mathrm{E}$ a W. Las precipitaciones caen con más intensidad en invierno y las estaciones equinocciales, con un mínimo muy marcado y corto en verano. El resultado es un balance hídrico casi siempre positivo, dado que la evapotranspiración es inferior a la precipitación.

3. Sierras Orientales: esta zona climática incluye desde la Sierra de Javalambre hasta las sierras de Lidón, Gúdar y el Pobo, además del curso alto del Alfambra. Las precipitaciones no son tan intensas como en la zona occidental y sólo se sobrepasan los $700 \mathrm{~mm}$. en los puntos más altos. Además del máximo de precipitación primaveral se 
produce uno secundario durante el otoño, debido al aumento de la importancia de las precipitaciones de levante. Estos relieves representan el límite de la zona de influencia del Mediterráneo.

\subsection{Situaciones sinópticas, precipitaciones y estacionalidad}

El análisis pluviométrico de las 42 avenidas incluye tanto volúmenes de lluvia como tipos de situación sinóptica. Los tipos sinópticos se han estudiado a partir de los Boletines Meteorológicos Diarios del I.N.M., que proporcionan cartografía sinóptica y datos sobre la presión y la temperatura.

Las situaciones sinópticas fuertemente inestables son las que producen las precipitaciones que forman la avenida. Estas situaciones pueden ser de dos tipos: por advección, cuando predominan los movimientos horizontales, o convectivas, cuando la inestabilidad se genera por movimientos verticales (Albentosa, 1989):

1. Advecciones del oeste (W): producidas por masas de aire polar marítimas ( $\mathrm{Pm}$ ). Siguiendo la circulación zonal, entran a la Península desde el Atlántico. Masas muy húmedas y relativamente frías. Producen líneas frontales asociadas a profundas borrascas atlánticas. Pueden tener un componente más SW con masas Pm de retorno. Estas situaciones sinópticas son abundantes todo el año pero son más habituales de octubre a mayo.

2. Advecciones del este (E): provocadas por varios tipos de masas tropicales. Unas provienen del Atlántico (Tm). Estas cruzan el estrecho de Gibraltar. Son muy húmedas, cálidas e inestables. Otras, son las Tropical continentales (Tc). Éstas proceden de África pero cogen humedad por el contacto más o menos largo con el Mediterráneo, por lo que se inestabilizan al llegar a la Península Ibérica. La inestabilidad en superficie no es muy acusada pero queda bien reflejada en los mapas de altura con grandes vaguadas de aire frío que llegan a estrangularse y formar "gotas frías". Son muy habituales en las estaciones equinocciales, sobretodo en otoño.

3. Tormentas: son de tres tipos: provocadas por ascensión de aire por recalentamiento de las capas bajas de la atmósfera en primavera y el verano. Después están las orográficas, generadas por el movimiento convectivo de una masa de aire húmeda e inestable para superar relieves importantes. Por último encontramos la tormentas frontales: asociadas a frentes fríos. Forman familias de "lineas de turbonada". Son más extensas que las anteriores. Muy frecuentes en primavera y verano. 


\section{A) Situaciones sinópticas}

Cabe destacar que del total de 42 casos analizados, casi la mitad muestran advecciones de tipo zonal. Les siguen en importancia los fenómenos convectivos y, en última posición, las advecciones procedentes del Este. Pero si analizamos la situación sinóptica que produce las lluvias intensas en cada cuenca, por separado, encontramos grandes diferencias (ver figura 5). Las características de las situaciones sinópticas individualizan de manera clara a cada cuenca. Por un lado contraponen la cuenca drenada por el Guadalaviar con la del Alfambra. La primera drena los relieves más occidentales de la cuenca. Estos, con una disposición NW-SE crean una barrera orográfica muy destacable a los vientos zonales, por lo que los frentes activos llegan a descargar volúmenes de precipitación muy importantes en la cabecera de la cuenca. La precipitación zonal genera el $60 \%$ de las avenidas del Guadalaviar. Esta misma situación sinóptica también origina avenidas en el Alfambra. Su cuenca, abierta al influjo del SW, recibe precipitaciones zonales importantes cuando los frentes son muy activos y logran rebasar los relieves más occidentales. Sólo producen el $28 \%$ de las avenidas del Alfambra, pues la Serranía de Albarracín produce sombra pluviométrica sobre la mayor parte de la depresión del Alfambra. En cambio, las avenidas generadas por advecciones procedentes del Mediterráneo son casi la mitad de los casos del Alfambra. Los vientos del E descargan grandes volúmenes de precipitación en los relieves septentrionales y orientales de la cuenca. Las avenidas que producen son

\section{SITUACIÓN SINÓPTICA}

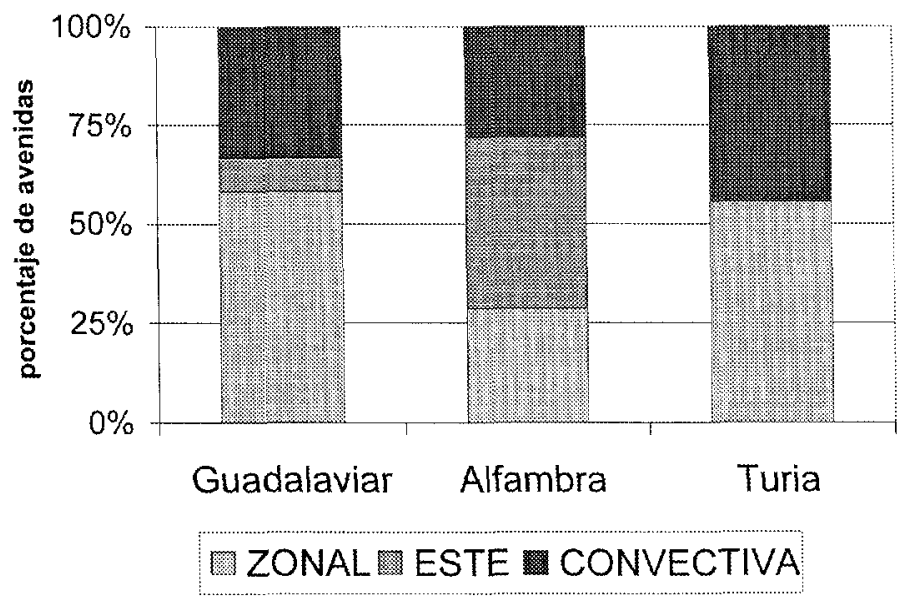

Figura 5. Porcentaje de avenidas en las cuencas analizadas según la situación sinóptica que las origina. Fuente I.N.M. Elaboración propia. 
importantes para esta cuenca, pero en su traslación hacia el Turia pierden rápidamente importancia, pues en la Zagra no encontramos ninguna avenida generada por este tipo de situación. En éste último aforo, las avenidas más habituales también se originan por frentes atlánticos (56\%). Las avenidas se forman, en muchos casos, en la cuenca del Guadalaviar y se trasladan aguas abajo sin rebajar excesivamente su pico. Debido a que todas las cuencas cuentan con relieves importantes y pueden llegar a registran radiaciones diurnas muy acusadas durante la época estival, las tormentas originan frecuentes avenidas en las tres cuencas aforadas. En todas registramos un número apreciable de casos. Llegan a generar un porcentaje de casos más elevado en La Zagra (44\%) que en las cuencas de cabecera, pero esto se debe a que en ellas hay un predominio mayor de las advecciones y en ésta producen más escorrentía los movimientos convectivos.

Si sectorizamos la cuenca alta del Turia en zonas según la importancia de unas u otras situaciones sinópticas, obtenemos el mapa de la figura 6 . Observamos que las precipitaciones de levante dominan una estrecha franja en el NE de la cuenca alta del Turia. Esta franja se corresponde con los relieves situados en la mitad oriental de la cuenca del Alfambra (Sierras de Lidón y Gúdar). En cambio las precipitaciones del WSW afectan preferentemente la Serranía de Albarracín y los relieves más occidentales del valle del Turia. La amplia zona central, ocupada por la depresión de TeruelAlfambra, queda aislada de las advecciones. En ella se registra un predominio de avenidas originadas por lluvias convectivas, elemento típico del clima continental que afecta a esta cuenca.

\section{B) Estacionalidad}

Cabe destacar que el 40\% de avenidas se producen durante los meses de invierno, seguidas en un $26 \%$ por las de primavera. Así pues, en los meses de invierno-primavera (diciembre-junio) se concentran las $2 / 3$ partes del total anual de avenidas. Contrariamente a lo que pasa en la zona litoral del Mediterráneo, el otoño no es una estación que registre la mayoría de avenidas (sólo se produce el 13\% de los casos). El verano sí es una estación donde tienen lugar bastantes avenidas (21`7\%). Esto es debido a que es la estación más lluviosa del año en muchos puntos de la cuenca por el frecuente desarrollo de fenómenos convectivos.

Si relacionamos las avenidas con los tipos de situación que las originan, vemos que las tormentas se producen fundamentalmente en verano, aunque también en primavera. La circulación zonal produce avenidas en invierno, cuando los frentes son más efectivos y, en mucha menor medida, en las estaciones de transición. También las advecciones del $\mathrm{E}$ tienden a tener un claro comportamiento estacional. Todas ellas se producen durante las estaciones equinocciales. 


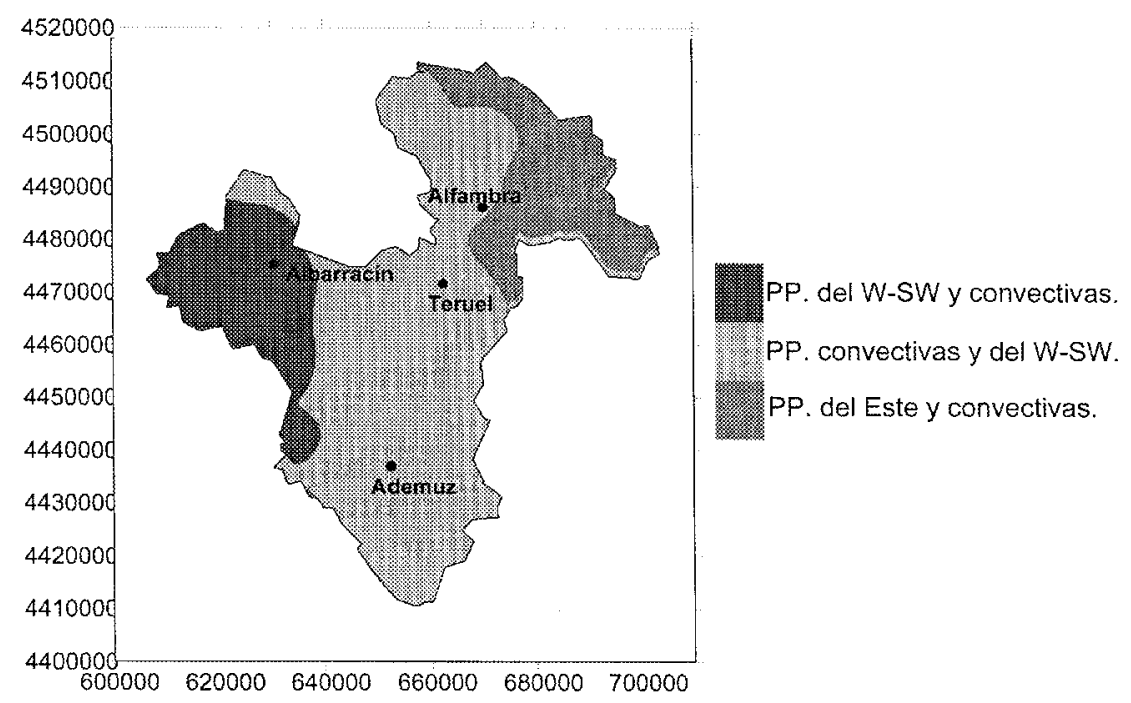

Figura 6. Zonificación de la cuenca alta del Turia según el predominio de tipos de tiempo inestables que provocan avenidas. Fuente: autor; Elaboración propia.

C) Intensidad

La medida de la intensidad queda condicionada en este estudio por la escala temporal del registro. Trabajamos con la lluvia total acumulada en 24 horas, por lo que las intensidades punta mucho más elevadas quedan enmascaradas en estas cifras. La principal característica de la precipitación máxima en nuestra cuenca es que registra muy pocos casos de cifras diarias muy elevadas. Así, el $58 \%$ de avenidas estudiadas están originadas por lluvias diarias inferiores a $50 \mathrm{~mm}$ y tan sólo uno de cada 5 episodios tiene una intensidad máxima diaria de más de $75 \mathrm{~mm}$.

Por cuencas, ver figura 7, las particularidades son destacables. En el Guadalaviar no se registra ningún temporal con una precipitación máxima inferior a $25 \mathrm{~mm}$. Esto es debido a la abundancia de suelos cársticos y al tipo de precipitación predominante. Las lluvias de intensidad débil no rebasan la alta capacidad de infiltración de los suelos calcáreos y apenas producen escorrentía superficial. Para que se produzca una avenida, los frentes atlánticos deben producir volúmenes considerables de precipitación. Al ser una zona afectada por frentes de manera consecutiva, la precipitación 


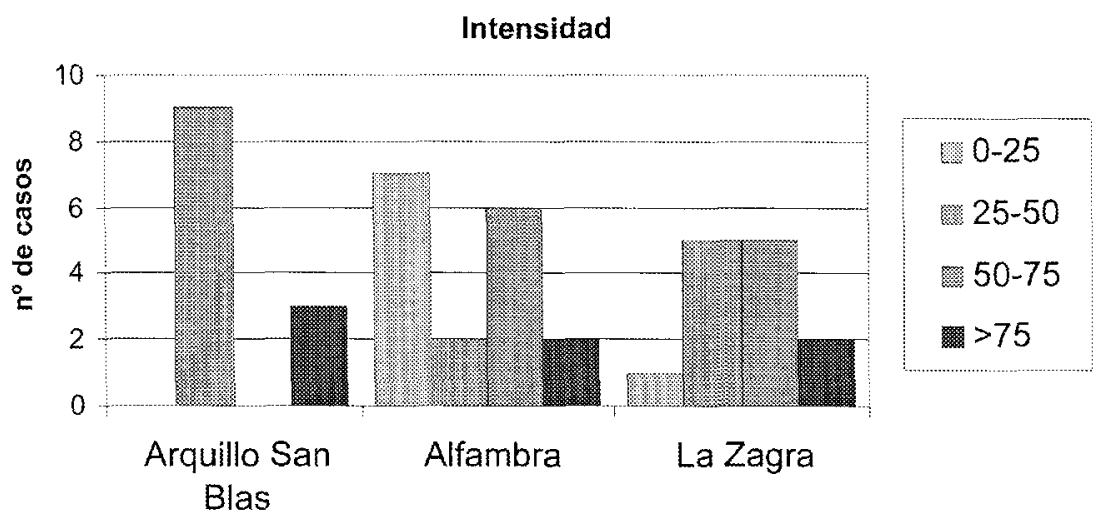

Figura 7. Intensidad diaria máxima de la precipitación que ha generado avenidas. Fuente: CHJ. Elaboración propia.

total de un episodio de lluvias intensas en esta cuenca sí que rebasa fácilmente los $100 \mathrm{~mm}$ en observatorios de cabecera. En cambio, en la cuenca del Alfambra hay muchos temporales con unas cifras inferiores a $25 \mathrm{~mm}$. Esto es debido a la abundancia de materiales impermeables que favorecen la escorrentía directa. Son frecuentes temporales con precipitaciones diarias entre 50 y $75 \mathrm{~mm}$ y algunos casos que superan esta última cifra. En La Zagra, donde en más de la mitad de los casos se superan los $50 \mathrm{~mm}$ diarios, se necesitan intensidades elevadas para hacer que la escorrentia superficial afecte a una cuenca con un tamaño bastante considerable. Son precipitaciones de diferentes tipo: grandes tormentas y advecciones del W y SW.

Si relacionamos la intensidad con la situación que origina la precipitación, hemos de señalar que las advecciones de levante provocan las intensidades más elevadas, pero son episodios muy escasos. La mayoría de las tormentas producen intensidades diarias elevadas, incluso superando los $75 \mathrm{~mm}$ diarios en algún caso. Por el contrario, los frentes atlánticos afectan a grandes superficies pero con una intensidad baja, por lo que la mitad de avenidas originadas por esta situación sinóptica tienen intensidades diarias inferiores a los $50 \mathrm{~mm}$. Los frentes que producen cifras más elevadas son los desarrollados durante el invierno, mientras que el resto producen intensidades más modestas. Esto es debido a que durante el invierno la circulación de la borrascas es más meridional y son más efectivas en su paso por la cuenca alta del Turia, mientras que el resto del año llegan desgastados. 


\subsection{Duración y volumen de las precipitaciones que originan avenidas}

Como acabamos de ver, la duración de la precipitación que origina avenidas depende fundamentalmente del tipo de situación que produce las lluvias fuertes. Los episodios de precipitación producidos por tormentas suelen tener una duración de uno o, a lo sumo, dos días de precipitación. En cambio, los episodios originados por frentes atlánticos suelen estar formados por bastantes días de precipitación, producida por el paso de uno o más frentes consecutivos. Un caso intermedio son los temporales de levante. Se trata de frentes formados por células de precipitación con una duración de 1 a 3 días.

Cuando mayor es la cuenca de drenaje, mayor es el volumen de precipitación necesario para la formación de la avenida. En el aforo de Arquillo San Blas estos volúmenes van desde $31^{\prime} 4 \mathrm{hm}^{3}$ hasta a $93^{\prime} 5 \mathrm{hm}^{3}$. En el Río Alfambra las avenidas están causadas por volúmenes más dispares, unos menos importantes $\left(9^{-7} \mathrm{hm}^{3}\right)$ y otros mayores $\left(126^{-} 5 \mathrm{hm}^{3}\right)$. Esta desigualdad de comportamiento se debe a diferencias de suelo. La cuenca del Guadalaviar cuenta con mayor presencia calcárea, mientras que la del Alfambra es más impermeable. En La Zagra los hectómetros cúbicos necesarios por formar una avenida muestran una gran variabilidad, entre $11^{\prime} 9$ y $376^{\prime} 9 \mathrm{hm}^{3}$.

El volumen de precipitación producido durante un episodio de lluvia intensa muestra una estrecha relación con la situación sinóptica que la ha originado. Analizando el número de casos y comparándolo con la media, se puede afirmar que las advecciones del W-SW producen volúmenes de precipitación inferiores a la media en $2 / 3$ de los episodios, sobre todo en el Turia y en el Alfambra, mientras que producen volúmenes más importantes en el Guadalaviar.'Así vemos que los frentes atlánticos son más efectivos en las sierras del W de la cuenca, mientras que llegan desgastados a zonas situadas a sotavento de estos relieves. Las situaciones de levante producen volúmenes de precipitación superiores a la media en un $87^{\circ} 5 \%$ de las avenidas. Las escasas situaciones de levante que afectan a nuestra cuenca son las más violentas como la que originó una avenida en el Alfambra en octubre de 1957. En lo que se refiere a las tormentas, debido a la mayor o menor inestabilidad que las originan, existen casos con volúmenes poco destacables, preferentemente en el Alfambra y Guadalaviar, y otros muy elevados en La Zagra.

\subsection{Características espaciales de las precipitaciones intensas}

Los principales factores que influyen en la distribución de las precipitaciones son la forma de la cuenca, el relieve, la situación geográfica respecto a las advecciones y la distancia existente entre los núcleos de máxima precipitación y el aforo. El análisis de esta tipología se realiza por cuencas aforadas: 
a) Guadalaviar: esta cuenca tiene una forma ovalada. El relieve más abrupto se concentra en la Sierra de Albarracín que, con una disposición NW-SE conforma la cabecera de la cuenca al W. Hacia la zona oriental el relieve se suaviza hasta las llanuras cercanas al embalse de Arquillo San Blas. El 80\% de los episodios de precipitaciones intensas que han originado avenidas tienen una distribución típica. Se producen los máximos de precipitación en los sectores de cabecera de la cuenca, al W y SW, mientras que hay descensos destacados hacia el E. Esta distribución típica es debida a que los relieves crean una barrera orográfica a los numerosos frentes Atlánticos que apenas afectan a la zona de sotavento. Los demás tipos de precipitación tienen una distribución más irregular y son poco representativos.

b) Alfambra: la cuenca está cerrada al E y al $\mathrm{N}$ por relieves más o menos enérgicos. En ellos es donde se suele concentrar la mayor cantidad de precipitación y no en la amplia depresión situada en su centro. Cuando las precipitaciones son de levante, se concentran en las sierras de Gúdar y septentrionales. Si son zonales, en estas mismas sierras o en la del Pobo. Las tormentas por su parte tienen una distribución anárquica.

c) La Zagra: la cuenca del Turia es mucho más compleja. Está formada por tres unidades morfoestructurales claramente diferenciadas. Al W una zona montañosa conformada por la $S^{a}$ de Albarracín y su prolongación hacia el sur. La zona central ocupada por la depresión de Teruel-Alfambra: una fosa tectónica del terciario que queda completamente cerrada porque el sector oriental también está conformado por una zona montañosa (sierras de Javalambre y Gúdar). Las precipitaciones convectivas, muy numerosas a la hora de producir avenidas, tienden concentrarse en zonas de montaña pero de manera irregular. Las zonales, las más importantes a la hora de producir avenidas, se concentran en las sierras occidentales y, en menor medida, en las caras de barlovento de Javalambre y Gúdar. Hemos de destacar la ausencia total de avenidas generadas en este aforo por precipitaciones de levante.

\section{Volúmenes de precipitación y avenidas}

En el presente apartado intentaremos relacionar los dos elementos fundamentales, es decir, avenidas y precipitaciones intensas. Se interrelacionarán y se observará como se produce el fenómeno de la conversión de lluvia en caudal útil como recurso hídrico. 


\subsection{Precipitaciones y escorrentía}

En este apartado nos centramos en el análisis de los volúmenes de precipitaciones que han generado avenidas, la escorrentía existente en el río y la que estas precipitaciones han generado. También analizamos su variación en las distintas cuencas analizadas y los factores que las determinan.

a) Volumen de precipitación: las precipitaciones que originan las avenidas no son muy intensas en la cuenca estudiada al tratarse de una zona interior entre relieves. Pese a todo, los volúmenes precipitados durante los episodios de crecida son bastante significativos. Suponen una media de $54 \mathrm{hm}^{3}$ en el Guadalaviar, $61 \mathrm{hm}^{3}$ en el Alfambra y $182 \mathrm{hm}^{3}$ en el Turia. Comparándolos con el área de cada cuenca hemos de destacar que las lluvias en el Guadalaviar son algo más abundantes que en el Alfambra y el Turia. Esto muestra que, en términos medios, es necesaria una mayor cantidad de precipitación para producir una avenida en el Guadalaviar que en las otras cuencas.

b) Volúmenes de escorrentía total y directa: las cifras medidas en los diferentes aforos analizados durante los días de crecida arrojan cifras mucho más reducidas que las de las precipitaciones. En el Guadalaviar las cifras varían entre los 3 y los $19 \mathrm{Hm}^{3}$, con una escorrentía total media de $8^{\prime} 5 \mathrm{hm}^{3}$ por avenida. Esta cifra supone tan sólo el $16 \%$ del volumen de agua precipitada. Esta media es aun más profunda en el Alfambra (11\%) pero con cifras aun más dispares entre $1 \mathrm{hm}^{3}$ y $16 \mathrm{hm}^{3}$. En el caso del Turia, la escorrentía total es más elevada en cuanto a cifras absolutas ( $68 \mathrm{hm}^{3}$ por crecida) pero no relativas, con un volumen medio de tan sólo $24 \mathrm{hm}^{3}$ por crecida, es decir, el $13 \%$ del volumen precipitado.

A estos valores absolutos de escorrentía total hay que descontar el flujo basal proveniente de las aguas sub-superficiales, que suponen una parte importante del volumen circulado en los ríos perennes. En el Alfambra el flujo basal supone el 39\% de la escorrentía durante los días de avenida, pero en el Guadalaviar y el Turia representa más del $45 \%$ del escurrimiento total que circuló durante esos días. Así que los volúmenes de escorrentía directa, producida por lluvias intensas que acaban de producirse, suponen volúmenes muy bajos. En el Guadalaviar tienen unos valores medios de $4^{7} 7 \mathrm{hm}^{3}$, algo más elevados que los del Alfambra $\left(3^{-} 8 \mathrm{hm}^{3}\right)$ y bastante inferiores a los del Turia en La Zagra $\left(11^{\prime} 8 \mathrm{hm}^{3}\right)$. Hay señalar, no obstante, que estos valores medios son muy relativos, pues están condicionados por el desigual tamaño de la cuenca. Si igualamos la serie, tomando las 12 principales avenidas de cada aforo, las medias obtenidas siguen manteniendo las diferencias. El río Guadalaviar produce escorrentías muy superiores al Alfambra.

c) Coeficiente de escorrentia: es la cifra resultante de relacionar el volumen de precipitación con el volumen de escorrentía producido como consecuencia directa de esa precipitación. El coeficiente de escorrentía directa nos da unas cifras medias para 
el Guadalaviar de 9\%, para el Alfambra del 10`8\% y para el Turia en La Zagra 9`9\%. Así pues, las cifras medias son muy similares en todos los aforos. Las principales avenidas de la cuenca alta del Turia producen un coeficiente de escorrentía media del 98\%. Así que, de toda el agua precipitada sobre la cuenca, apenas el 10\% se convierte en caudal. El restante $90 \%$ se considera abstracciones hidrológicas donde entra el agua evapotranspirada, infiltrada, etc. Comparando los porcentajes de escorrentía con las otras cuencas mediterráneas encontramos que para la Rambla de la Viuda, un curso efímero castellonense, Segura (1990) dan un valor medio de 4\%68\%. En el caso de ramblas con cuencas pequeñas como las valencianas del Carraixet y Rambla de Poyo, Camarasa (1995) les atribuye unas cifras de 5 y 9\% respectivamente. En el caso de ríos perennes mediterráneos Palanca (1998) da un porcentaje medio de 10\% $9 \%$ para las principales avenidas del Palancia. Esta última cifra es muy similar a los porcentajes obtenidos en nuestra zona de estudio, pero estudios en curso nos muestran que en ríos perennes este coeficiente es muy variable. El río Magro arroja cifras sobre el $6 \%$, mientras que el Serpis en Beniarrés, una media mucho más elevada, del 17\% (Morell, en prensa).

La relación entre el porcentaje de escorrentía y los factores litológicos es muy estrecha. El Guadalaviar, con una cuenca con regulación cárstica, tiene un coeficiente de escorrentía ligeramente inferior al del Alfambra, con una cuenca más impermeable. Las diferencias no son mayores porque las pendientes, otro factor determinante de la escorrentía, son muy elevadas en el primero y tienden a magnificar las avenidas, compensando el factor cárstico. En lo que se refiere a otros factores que determinan el porcentaje de escorrentía hay que destacar la estrecha relación entre la duración total de la avenida y este parámetro. Cuando más días dura un episodio más elevado es el coeficiente de escorrentía. La razón fundamental es que se contabiliza como escorrentía directa una parte del agua infiltrada (flujo subsuperficial) que vuelve de modo relativamente rápido al cauce de los ríos en forma de flujo de retorno. La separación en el hidrograma de este flujo y el flujo directo es prácticamente imposible. Este último depende del grado de saturación del suelo.

La relación positiva entre duración total (D) y el porcentaje de escorrentía se produce en el $90 \%$ de las avenidas. Falta analizar si el flujo subsuperficial es el responsable de que el flujo basal se sitúe casi siempre en niveles superiores a los registrados antes del inicio de la avenida, aunque pensamos que no, que el ascenso del flujo basal es debido a las aportaciones de acuíferos colgados de respuesta rápida con fuentes efímeras. Un ejemplo son los "Caños de Gúdar" en la cabecera del Alfambra; manantiales de tipo "trop plein" que funciona durante algunos días tras fuertes tormentas o tras episodios primaverales de lluvias prolongadas.

En la relación entre la escorrentía directa y los parámetros pluviométricos no hay una clara determinación en la conversión lluvia-caudal. Apenas influyen parámetros como intensidad y distribución de la precipitación. En cambio, si que influye la época del año en la que se produce la crecida. Las avenidas con coeficientes de escorren- 
tía elevados (más del 10\%) se producen fundamentalmente durante el invierno. En cambio el $45 \%$ de avenidas con valores bajos (por debajo del $10 \%$ ) se producen durante el verano-otoño. La razón la encontramos en que durante el invierno las lluvias son, en general, más continuas, por la presencia reiterada de los frentes del WSW. Esta situación provoca una disminución de la capacidad de infiltración e, incluso, la saturación de los suelos. La escorrentía se ve más favorecida. En cambio, durante el verano-otoño, aunque se registren precipitaciones con grandes volúmenes, funciona más la infiltración, debido a que los suelos mantienen una gran capacidad de infiltración.

\subsection{Avenidas y recursos hídricos}

Para poder valorar qué volumen de recurso hídrico suponen las avenidas analizadas, hemos tomado como referencia los embalses de esta cuenca. En el caso del Guadalaviar el embalse utilizado es el de Arquillo San Blas, situado en su cuenca baja, cerca de la capital provincial, que cuenta con $22 \mathrm{hm}^{3}$ de capacidad. En el caso de la Zagra compararemos los volúmenes con el embalse de Benagéber, en cuya cabecera se encuentra este aforo. Este gran embalse del interior valenciano cuenta con 228 $\mathrm{hm}^{3}$. Debido a la inexistencia de embalses, hasta la fecha, en la cuenca del Alfambra, relacionamos los volúmenes producidos en esta cuenca con la capacidad de Arquillo San Blas, debido a que ambas cuencas tienen unas superficies más o menos semejantes. Los volúmenes totales precipitados en los diferentes episodios de lluvia intensa suelen superar la capacidad de almacenamiento de estos embalses. Así, las lluvias intensas caídas en la cuenca del Guadalaviar y que han formado una avenida, siempre producen volúmenes superiores a la capacidad máxima de Arquillo San Blas. Por su parte, La Zagra registra tan sólo 4 avenidas producidas por volúmenes intensos que superan la capacidad de Benagéber. El resto de avenidas no supera su capacidad máxima de almacenamiento.

El volumen de agua que circula por los aforos durante los días de crecida nunca supera la capacidad de Arquillo San Blas ni de Benagéber en los aforos estudiados. La escorrentía total del Guadalaviar y del Alfambra supone una media del 38\% y $31 \%$ del volumen del embalse turolense en el conjunto del total de episodios. Por su parte, la escorrentía total de las avenidas de la Zagra supone un 11\% de media de la capacidad del Aforo de Benagéber, con un máximo del 30\% en el episodio del 19-3-69. Pero estas cifras no son representativas, pues en el aforo de un río perenne se unen los flujos directos, provenientes de las recientes lluvias, y los de base, consecuencia de la descarga continua del acuífero. Estos últimos suelen representar un $40 \%$ la escorrentía total durante los días de avenida. Si nos centramos en el estudio de la escorrentía directa, consecuencia de lluvias fuertes, los volúmenes que conforman los picos de las avenidas son casi irrelevantes. En el caso del río Guadalaviar suponen como máximo $14^{\prime} 3 \mathrm{hm}^{3}$, es decir, el $65 \%$ de la capacidad máxima de Arquillo San 
Blas. Pero, como media, la escorrentía directa del Guadalaviar supone apenas el 21\% de la capacidad de Arquillo San Blas. Más escasa es la escorrentía directa del Alfambra. Este río, con una cuenca algo mayor, produce escorrentías directas que suponen entre el $4 \%$ y el $39 \%$ de la capacidad total del embalse turolense. En La Zagra, la escorrentía directa que pasa por el aforo supone, de media, el 5\% de la capacidad del embalse de Benagéber. Estas cifras reflejan la poca relevancia de las avenidas producidas por este río si tenemos en cuenta que la mayor avenida registrada en La Zagra, produce $30 \mathrm{hm}^{3}$ de escorrentía directa, lo que supone tan sólo el 13\% de la capacidad del embalse de Benagéber.

\section{Conclusiones}

Cabe destacar que las avenidas producidas en la cuenca alta del río Turia son bastante modestas. Esto se debe, principalmente, a la situación de la cuenca en una zona interior formada por una depresión rodeada de relieves en su periferia. Este factor produce un aislamiento de ésta frente a la entrada efectiva de las masas de aire inestable. Así, los volúmenes de precipitación intensa son bastante modestos, pues las sierras periféricas convierten la depresión de Teruel-Alfambra en una zona de sombra pluviométrica a las masas atlánticas y mediterráneas. Las tormentas, abundantes por su carácter de clima continental, no tienen fuentes de humedad cercanas que les permitan precipitar grandes cantidades de agua. Estas afirmaciones coinciden con los estudios de Davy (1978). Sobre las avenidas en la cuenca del Ebro afirma, a través de varios ejemplos, que las avenidas producidas por los afluentes provenientes del Sistema Ibérico son poco frecuentes y poco importantes.

Centrándonos en las características de las avenidas, sí que se observa una clara oposición entre los dos colectores principales de cabecera. Las avenidas del Guadalaviar son bastante más significativas que las del Alfambra. Esto sucede a pesar de que las litologías que favorecen la escorrentía abundan más en la segunda cuenca. Esta situación es debida a que las lluvias son mucho más frecuentes y abundantes en los sectores de cabecera del Guadalaviar (Montes Universales) por la llegada continua de frentes atlánticos durante el invierno, mientras que la cuenca del Alfambra está aún más aislada de las masas inestables.

Por otro lado, la elevada evapotranspiración, suelos desfavorables, la infiltración y la falta de pendientes en el sector central de la cuenca del Turia produce una baja tasa de conversión lluvia-caudal. Así, el coeficiente de escorrentía apenas llega al 10\%. Las aguas de crecida que llegan a los embalses de estas cuencas no suponen un recurso hídrico importante comparándolo con el generado por el elevado y continuo caudal base. Estas avenidas apenas suponen un riesgo climático para la población, pues los embalses, incluso los de pequeña capacidad de cabecera, pueden laminar- 
las y almacenarlas para paliar las falta de agua en esta zona interior semiárida. Cuando se construya el embalse de los Alcamines, éste laminará y recogerá las avenidas del Alfambra. Además de los embalses, el verdadero recurso hídrico se forma por la fuerte infiltración que hay en la cuenca alta del Turia que se traduce en la presencia de numerosas surgencias y fuentes que producen un gran volumen de caudal base a lo largo del año que permiten crear un recurso hídrico anual elevado.

\section{Bibliografía}

Albentosa, L.M. (1989): Las precipitaciones extraordinarias en Cataluña. En Avenidas fluviales e inundaciones en la cuenca del Mediterráneo. Instituto Universitario de Geografía, Universidad de Alicante. pp 5165.

Aparicio, F. J. (1999): Fundamentos de bidrologia de superficie. México, Limusa, $303 \mathrm{pp}$.

Camarasa, A. M. (1995): Génesis de crecidas en pequeñas cuencas semiáridas. Barranc de Carraixet y Rambla de Poyo. Valencia, M.O.P.T y C.H.J., 251pp.

Davy, I. (1978): lEbre, etude bydrologique. Lille, Université de Lille III, 803pp.

Dunne, T. (1978): Water in Environmental Planning. San Francisco, Freeman, 808pp.

Ebdon, D. (1982): Estadística para geógrafos. Barcelona. Oikos tau, 348pp

Ferrer Polo, F.J. (1992): Recomendaciones para el cálculo bidrometeorológico de avenidas. Madrid, CEDEX, 75pp.

Font Tullot, I. (1983): Climatologia de España y Portugal. Madrid, INM, 295pp.

Gutiérrez Elorza, M. y Peña Monne, J.L. (1990): Las formas del relieve de la provincia de Teruel. Teruel, Instituto de Estudios Turolenses, 66pp.

Llamas, J. (1993): Hidrologia general, principios y aplicaciones. Bilbao, Universidad del País Vasco, 635pp.
Manning, J. C. (1997): Applied principles of bydrology. New Jersey, Prentice Hall, 276pp.

Olcina, J. (1994): Riesgos climáticos en la Peninsula Ibérica. Madrid, Penthalon, 440pp.

Morell, J (1999): Les revingudes de la conca alta del Turia. Valencia. Tesis de licenciatura. Dpto. de Geografía-Universitat de València. 241pp.

Morell, J. (en prensa). Análisis comparado de las avenidas de los rios Magro y Serpis.

Navarro, F. (1991): El sistema bidrográfico del Guadalentin. Murcia, Cuadernos técnicos de la Consejería de Política Territorial, Obras Públicas y Medio Ambiente. 256pp.

Palanca Galindo, J. I. (1998): Análisis bidrológico de las avenidas del alto Palancia. Periodo 1960-90. Trabajo fin de carrera, Dpto. de Geografia-Universitat de València. $144 \mathrm{pp}$.

Peña, J. L., Cuadrat, J. M. y Sánchez, M. (2002): El clima de la provincia de Ternel. Teruel, Instituto de Estudios Turolenses.

Pérez Cueva, A. J. (1988): Geomorfología del Sector Ibérico valenciano entre los rios Mijares y Turia. Valencia, Dpt. Geografia, Universitat de València. 217pp.

Sánchez Fabre, M. (1990): Variaciones interanuales del balance hídrico en Teruel. Geographicalia, $\mathrm{n}^{\circ}$ 27, pp. 199-223. 
Sánchez Fabre, M. (1993): Aportación al estudio hidrológico del río Alfambra (provincia de Teruel). Geograpbicalia, $\mathrm{n}^{\circ} 30, \mathrm{pp}$. 347-360.

Sánchez Fabre, M. y Peña Monné, J.L. (1987): Aportación al conocimiento del régimen fluvial de los ríos Alfambra y Guadalaviar a su paso por Teruel. Temiel, pp 27-48.

Segura Beltrán, F. (1990): Las ramblas valencianas. Valencia, Dpt. Geografia, Universitat de València, 229pp.

Tabla 1. Principales avenidas producidas en los diferentes aforos estudiados de la cuenca alta del Turia durante el período 1950-90.

\begin{tabular}{|c|c|c|}
\hline \multicolumn{3}{|c|}{ Arquillo San Blas } \\
\hline Avenida & Q máx. & QED $_{x}$ \\
Fecha & $\mathrm{m}^{3} / \mathrm{seg}$ & l/seg/km \\
\hline $19 / 11 / 1967$ & 37,3 & 40,3 \\
$24 / 02 / 1969$ & 22,6 & 24,5 \\
$19 / 03 / 1969$ & 56,1 & 60,6 \\
$30 / 04 / 1969$ & 20,4 & 22,0 \\
$06 / 01 / 1970$ & 24,9 & 26,9 \\
$14 / 05 / 1971$ & 17,5 & 18,9 \\
$29 / 07 / 1972$ & 19,5 & 21,0 \\
$27 / 02 / 1978$ & 21,9 & 23,7 \\
$29 / 01 / 1979$ & 15,7 & 17,0 \\
$12 / 02 / 1979$ & 15,4 & 16,6 \\
$02 / 06 / 1979$ & 16,2 & 17,5 \\
$28 / 06 / 1988$ & 17,1 & 18,4 \\
\hline
\end{tabular}

\begin{tabular}{|c|c|c|}
\hline \multicolumn{3}{|c|}{ Teruel-Alfambra } \\
\hline Avenida & Q máx. & QED $_{x}$ \\
Fecha & $\mathrm{m}^{3} / \mathrm{seg}$ & //seg/Km \\
\hline $26 / 05 / 1956$ & 15,9 & 12,0 \\
$13 / 10 / 1957$ & 21,5 & 16,2 \\
$20 / 12 / 1958$ & 18,3 & 13,8 \\
$06 / 08 / 1959$ & 12,2 & 9,2 \\
$22 / 11 / 1959$ & 20,1 & 15,1 \\
$25 / 01 / 1960$ & 15,6 & 11,8 \\
$18 / 02 / 1960$ & 12,2 & 9,2 \\
$14 / 10 / 1962$ & 12,3 & 9,2 \\
$31 / 05 / 1963$ & 12,3 & 9,2 \\
$09 / 04 / 1969$ & 11,7 & 8,8 \\
$02 / 07 / 1969$ & 11,5 & 8,7 \\
$25 / 07 / 1969$ & 13,9 & 10,5 \\
$06 / 10 / 1969$ & 12,4 & 9,4 \\
$06 / 01 / 1970$ & 20,0 & 15,1 \\
$20 / 05 / 1971$ & 17,2 & 12,9 \\
$23 / 07 / 1975$ & 15,2 & 11,5 \\
$21 / 05 / 1977$ & 19,9 & 15,0 \\
\hline
\end{tabular}

\begin{tabular}{|c|c|c|}
\hline \multicolumn{3}{|c|}{ La Zagra } \\
\hline Avenida & Q máx. & $\begin{array}{c}\text { QED } \\
\text { Fecha }\end{array}$ \\
$\mathrm{m}^{3} /$ seg & l/seg/Km² \\
\hline $10 / 07 / 1952$ & 43,3 & 10,7 \\
$27 / 05 / 1956$ & 62,0 & 15,3 \\
$02 / 09 / 1957$ & 53,7 & 13,3 \\
$16 / 10 / 1957$ & 92,4 & 22,8 \\
$05 / 09 / 1959$ & 50,7 & 12,5 \\
$29 / 01 / 1960$ & 65,1 & 16,1 \\
$20 / 02 / 1960$ & 61,3 & 15,1 \\
$08 / 06 / 1960$ & 57,8 & 14,3 \\
$01 / 11 / 1960$ & 49,6 & 12,2 \\
$19 / 03 / 1969$ & 107,2 & 26,5 \\
$14 / 05 / 1971$ & 60,5 & 14,9 \\
$23 / 08 / 1983$ & 51,1 & 12,6 \\
$29 / 06 / 1988$ & 54,9 & 13,5 \\
\hline
\end{tabular}

Fuente: CHJ. Elaboración propia.

Tabla 2. Periodos de retorno esperados para las avenidas producidas en las cuencas analizadas para $2,5,10,20$ y 50 años. Las cifras se expresan en m3/seg.

\begin{tabular}{cccccc} 
Aforo: & 2 años & $\mathbf{5}$ años & $\mathbf{1 0}$ años & $\mathbf{2 0}$ años & $\mathbf{5 0}$ años \\
\hline Guadalaviar & 12,7 & 24,8 & 38 & 62,2 & 79,2 \\
Alfambra & 6,7 & 15,5 & 20 & 21,3 & 27,9 \\
La Zagra & 28,4 & 50,8 & 61,5 & 92,2 & 130,7 \\
\hline
\end{tabular}

Fuente: CHJ. Elaboración propia. 
Tabla 3. Parámetros que caracterizan a las avenidas de la cuenca alta del Turia.

\section{Teruel-Alfambra:}

Avenida: Q. máx. Magnitud. Dt Duración Da Ascenso Dd Descenso Morfología Estación total

\begin{tabular}{|c|c|c|c|c|c|c|c|c|c|c|c|}
\hline 1 & $26 / 05 / 56$ & $15^{\prime} 9$ & Grande & 4 & corta. & 2 & respuesta rápida & 2 & brusca & simple & primavera \\
\hline 2 & $13 / 10 / 57$ & 215 & Grande & 8 & normal & 2 & respuesta rápida & 6 & normal & simple & otoño \\
\hline 3 & $20 / 12 / 58$ & $18 \cdot 3$ & Grande & 13 & larga & 6 & respuesta normal & 7 & normal & doble & otoño \\
\hline 4 & $06 / 08 / 59$ & $12^{-2}$ & Ordinaria & 3 & corta & 2 & respuesta rápida & 1 & brusca & simple & verano \\
\hline 5 & $22 / 11 / 59$ & $20^{\prime} 1$ & Grande & 11 & normal & 3 & respuesta rápida & 9 & suave & simple & otoño \\
\hline 6 & $25 / 01 / 60$ & 156 & Ordinaria & 9 & normal & 3 & respuesta rápida & 6 & normal & doble & invierno \\
\hline 7 & $18 / 02 / 60$ & $12 \% 2$ & Ordinaria & 8 & normal & 2 & respuesta rápida & 6 & normal & simple & invierno \\
\hline 8 & $14 / 10 / 62$ & $12^{\prime} 2$ & Ordinaria & 8 & normal & 3 & respuesta rápida & 5 & normal & simple & otoño \\
\hline 9 & $31 / 05 / 63$ & $12^{\prime} 2$ & Ordinaria & 14 & larga & 10 & respuesta lenta & 4 & brusca & doble & primavera \\
\hline 10 & $09 / 04 / 69$ & $11^{\prime} 7$ & Ordinaria & 15 & larga & 6 & respuesta normal & 9 & suave & simple & primavera \\
\hline 11 & $02 / 07 / 69$ & 115 & Ordinaria & 10 & normal & 2 & respuesta rápida & 8 & suave & simple & verano \\
\hline 12 & $25 / 07 / 69$ & $13^{\prime} 9$ & Ordinaria & 9 & normal & 3 & respuesta rápida & 6 & normal & simple & verano \\
\hline 13 & $06 / 10 / 69$ & $12 \%$ & Ordinaria & 7 & corta & 3 & respuesta rápida & 4 & brusca & simple & otoño \\
\hline 14 & $06 / 01 / 70$ & $20^{-1}$ & Ordinaria & 10 & normal & 4 & respuesta normal & 6 & normal & simple & invierno \\
\hline 15 & $20 / 05 / 71$ & 172 & Ordinaria & 19 & larga & 9 & respuesta lenta & 10 & suave & compleja & primavera \\
\hline 16 & $23 / 07 / 75$ & 152 & Ordinaria & 6 & corta & 2 & respuesta rápida & 4 & brusca & simple & verano \\
\hline 17 & $21 / 05 / 77$ & $19^{\circ} 9$ & Ordinaria & 14 & larga & 4 & respuesta normal & 10 & suave & simple & primavera \\
\hline
\end{tabular}




\section{Arquillo San Blas.}

Avenida: Q. máx. Magnitud. Dt Duración Da Ascenso Dd Descenso Morfología Estación total

$1 \quad 19 / 11 / 67 \quad 373$ extraordinaria 6 corta 4 respuesta normal 2 brusca simple otoño

$224 / 02 / 69 \quad 226 \quad$ grande $\quad 10$ normal 6 respuesta normal 4 normal compleja invierno

3 19/03/69 56¹ extraordinaria 9 corta 7 respuesta lenta 2 brusca compleja invierno

$430 / 04 / 69 \quad 20^{-4}$ grande 10 normal 4 respuesta normal 6 suave simple primavera

$5 \quad 06 / 01 / 70 \quad 24^{9} 9$ extraordinaria 10 normal 3 respuesta rápida 7 suave simple jnvierno

6 14/05/71 $17 \% 4$ Grande 5 corta 4 respuesta normal 1 brusca simple primavera

$729 / 07 / 72 \quad 19^{\circ} 4$ Grande 6 corta 3 respuesta rápida 3 brusca simple verano

$827 / 02 / 78 \quad 21^{\prime} 9$ Grande 14 larga 5 respuesta normal 9 suave compleja invierno

$929 / 01 / 79 \quad 157$ Grande $\quad 7$ corta 3 respuesta rápida 4 normal compleja invierno

$10 \quad 12 / 02 / 79 \quad 154$ Grande 10 normal 8 respuesta lenta 2 brusca simple invierno

$1202 / 06 / 79 \quad 162$ Grande 6 corta 3 respuesta rápida 3 brusca simple primavera

$1328 / 06 / 88 \quad 17^{\prime} 1$ Grande 12 normal 6 respuesta normal 6 suave compleja verano 
La Zagra.

Avenida: Q. máx. Magnitud. Dt Duración Da Ascenso Dd Descenso Morfología Estación total

\begin{tabular}{|c|c|c|c|c|c|c|c|c|c|c|c|}
\hline 1 & $10 / 07 / 52$ & 433 & Ordinaria & 4 & corta & 2 & respuesta rápida & 2 & brusca & simple & verano \\
\hline 2 & $27 / 05 / 56$ & 621 & grande & 7 & corta & 2 & respuesta rápida & 5 & suave & simple & primavera \\
\hline 3 & $02 / 09 / 57$ & 537 & Ordinaria & 8 & normal & 6 & respuesta normal & 2 & brusca & simple & verano \\
\hline 4 & $16 / 10 / 57$ & 924 & grande & 6 & corta & 3 & respuesta rápida & 3 & normal & simple & otoño \\
\hline 5 & 05/09/59 & $50 \div 7$ & Ordinaria & 4 & corta & 2 & respuesta rápida & 2 & brusca & simple & verano \\
\hline 6 & $29 / 01 / 60$ & 651 & grande & 9 & normal & 6 & respuesta normal & 3 & normal & simple & invierno \\
\hline 7 & $20 / 02 / 60$ & 612 & grande & 9 & normal & 3 & respuesta rápida & 6 & suave & doble & invierno \\
\hline 8 & $08 / 06 / 60$ & 577 & Ordinaria & 7 & corta & 4 & respuesta normal & 3 & normal & simple & primavera \\
\hline 9 & $01 / 11 / 60$ & $49^{\prime} 5$ & Ordinaria & 10 & normal & 8 & respuesta lenta & 2 & brusca & compleja & otoño \\
\hline 10 & $19 / 03 / 69$ & $107^{\prime} 2$ & xtraordinaria & 11 & normal & 7 & respuesta lenta & 4 & normal & simple & invierno \\
\hline 12 & $14 / 05 / 71$ & $60^{\prime} 5$ & Ordinaria & 7 & corta & 3 & respuesta rápida & 4 & normal & simple & primavera \\
\hline 13 & $23 / 08 / 83$ & $51^{\prime} 1$ & Ordinaria & 5 & corta & 3 & respuesta rápida & 2 & brusca & simple & verano \\
\hline 14 & $29 / 06 / 88$ & 549 & Ordinaria & 10 & normal & 4 & respuesta normal & 6 & suave & doble & verano \\
\hline
\end{tabular}

Fuente: CHJ. Elaboración propia. 